\title{
Additive manufacturing by means of laser-aided directed metal deposition of titanium wire
}

\author{
Fabrizia Caiazzo ${ }^{1}$
}

Received: 2 November 2017 / Accepted: 8 February 2018 / Published online: 24 February 2018

(C) The Author(s) 2018. This article is an open access publication

\begin{abstract}
A number of innovative technologies are offered in the literature to the purpose of additive manufacturing. Among them, directed metal deposition of wire by means of laser beam is receiving increasing interest since important advantages are benefited in comparison with its powder-based counterpart. Nevertheless, a number of issues must be addressed: this paper aims to provide further understanding of the technology to give grounds to actual applications in an industrial environment. Single trace deposition of Ti-6Al-4V wire over homologous substrate is investigated; the laser power, the processing speed, and the amount of fed metal is changed. The geometrical responses (i.e., trace width, height, depth, shape angle, and dilution) in the cross-section are investigated as a function of the processing parameters. Namely, a global clear view of the responses is given as a function of power and deposited wire mass per unit time. Furthermore, possible occurrence of micro pores is discussed with respect to common international standards. Eventually, an investigation about changes in both the microstructure and the microhardness is addressed: an increase of hardness in the fusion zone is noticed as a consequence of non-diffusional martensitic transformation of the original $\alpha-\beta$ phases upon rapid cooling, with reduced extent of the heat-affected zone below $0.4 \mathrm{~mm}$.
\end{abstract}

Keywords Laser directed metal deposition · Titanium alloy $\cdot$ Additive manufacturing $\cdot$ Wire deposition

\section{Introduction}

In the frame of green manufacturing, proper actions of maintenance and overhaul are required to the purpose of cost saving preventing part replacement [1]. Moreover, a reduction of waste is aimed by means of additive fabrication in comparison with traditional, subtractive technologies [2]. These issues are deemed to be of special impact for high-price sensitive products, such as Ti-based components [3]. As a consequence, extensive investigations led to a number of possible solutions falling within the wide family of layer-by-layer additive manufacturing (AM) [4].

Among these, laser-aided directed metal deposition (DMD) is thought to be capable of both producing near-net-shape parts and performing repair by means of addition of material [5]. Indeed, free of cracking laser weldability and compliance with tight standards of Ti-based parts has been proven in even

Fabrizia Caiazzo

f.caiazzo@unisa.it

1 Department of Industrial Engineering, University of Salerno, Via Giovanni Paolo II 132, Fisciano, Italy demanding environments such as automotive and aerospace $[6,7]$.

In laser metal DMD, a laser beam is used as heat source to scan the surface, thus creating a melting pool over an existing substrate. Since metal impinging, the pool is fed concurrently (i.e., in single-stage processing) [8], a deposited metal trace results, with metallurgical bonding to the substrate thanks to fusion and diffusion. Side overlapping of the individual laser traces is required to process wider surfaces on $3 \mathrm{D}$ complex geometries [9]. As a focused heat is provided, thermal affection is reduced and precision is enhanced in comparison with other means of thermal heating.

At present, both powder and wire are being considered as feedstock. It is worth noting that metallic wires are reported to be easier to stock and to produce in comparison with powder [10]; moreover, a reduction of costs and waste, an improvement in deposition efficiency in conjunction with a cleaner process environment without metal dust pollution is expected [11], although the influence of wire properties on the process quality must be further investigated $[8,10]$, as process stability, proper surface quality, bonding strength, and soundness are reported to be challenging and highly dependent on the processing parameters [12]. 


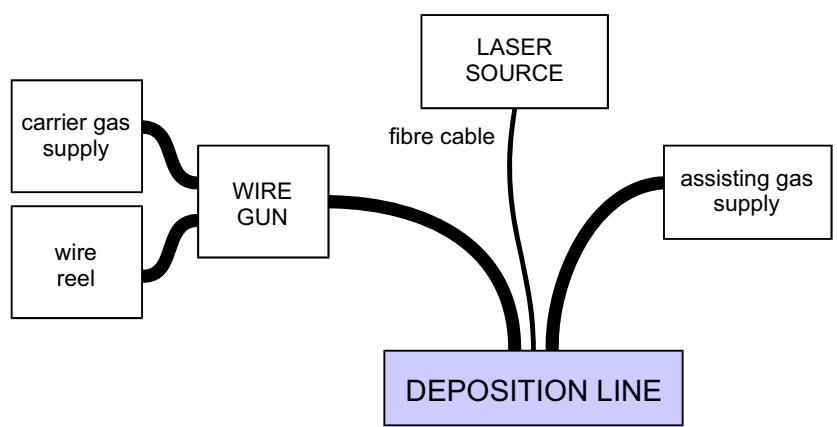

Fig. 1 Scheme for wire-based, laser-aided DMD

Given these, a number of research papers have been developed dealing with the subject of wire-based, laser-aided DMD to different purposes such as coating and repairing, even including the fabrication of thin-wall structures [10]. The device and the operating setup may differ depending on the metal and the available equipment [13]. Therefore, a number of solutions have been proposed in the literature. Defocusing of the laser beam is considered in general, to provide a larger spot with respect to the size of the metal wire $[10,11,14]$. A deposit width 5 to 15 times the wire diameter is reported in single deposition $[15,16]$, hence decreasing the geometrical resolution and the effectiveness of the part, depending on the application.

Specific additional challenges must be addressed when DMD is performed by means of titanium wire. Namely, since titanium is prone to oxidation, a proper device to shield both the melted pool and the metal during solidification must be set. An argon-flooded box [14, 17] or chamber [16] has been proposed and proved to be effective for Ti-6Al-4V; nevertheless, this would be impractical for larger parts and economically nonviable since a permanent inert flow must be allowed. Other documented researches in this respect are devoted to optimization of the process with conventional heat sources. Tungsten inert gas welding has been shifted to AM [18], the process being valuable for small quantities. Moreover, plasma arc resulted in an overall cost of $15 \%$ approximately with respect to laser [19], although unfeasible for thin parts or high-precision applications; hence, a hybrid system to lay Ti-wire metal over parts resulting from powder bed-based AM has been conceived [20].

Table 1 Main technical features of the laser source

\begin{tabular}{lc}
\hline Parameter & Value \\
\hline Maximum output power $[\mathrm{kW}]$ & 10.0 \\
Operating nominal wavelength $[\mathrm{nm}]$ & 1030 \\
Beam parameter product $[\mathrm{mm} \times \mathrm{mrad}]$ & 6.0 \\
Core diameter of the delivering fiber $[\mu \mathrm{m}]$ & 300 \\
Spot size of the laser beam on the surface $[\mathrm{mm}]$ & 0.3 \\
\hline
\end{tabular}

As regarding the mechanical properties, when performing multiple deposition, anisotropy is expected as a consequence of layer-by-layer addition and has been addressed in the literature both for wire and powder deposition [21]. Indeed, higher microhardness results in the reported metal thanks to finer microstructure [10]; moreover, the higher the power, the larger the grains [14]. The dynamic strength upon deposition generally exceeds the properties of wrought metal [17]. Interestingly, as-deposited Ti-6Al-4V samples showed higher tensile strength than their stress-relieved counterpart; indeed, a coarser and low ductile microstructure has been reported after stress relief [16].

Taking into account the existing knowledge about laseraided and general DMD of metallic wire, a device to shield the reported metal is preliminarily presented in this paper to address the challenges of titanium oxidation; then, the effect of the processing parameters on the geometry and the resulting microhardness in both the fusion zone and the heat-affected zone (HAZ) is discussed. Grounds are given for actual industrial application.

\section{Experimental procedure}

To perform AM by means of DMD, a deposition line is required involving a number of base components [22], irrespective of the form of the feedstock supply. To the purpose of this work (Fig. 1), a fiber-delivered IPG Yb YLS-10000, Yb:YAG fiber laser source operating in continuous wave emission (Table 1), has been considered.

The movement of the laser head, FLW-D50, has been accomplished by a prototype non-commercial gantry system with dedicated controller. A commercial Abicor Binzel MFS-V3 wire gun, to be moved with the laser head, has been employed to provide the feeding metal (Fig. 2); the wire metal has been fed from the front, in contrary direction with respect to the travelling speed. An angle of $50^{\circ}$ has been set with respect to the substrate, although lower angles have been suggested by some authors to improve the surface quality when considering stainless steel [23]; in this case, the angle is a

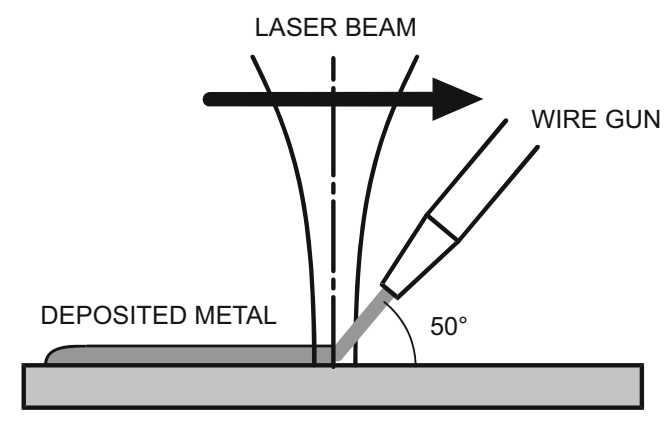

Fig. 2 Positioning of the wire gun over the processing line 
Fig. 3 Positioning of the additional devices to shield the reported metal and the melting pool
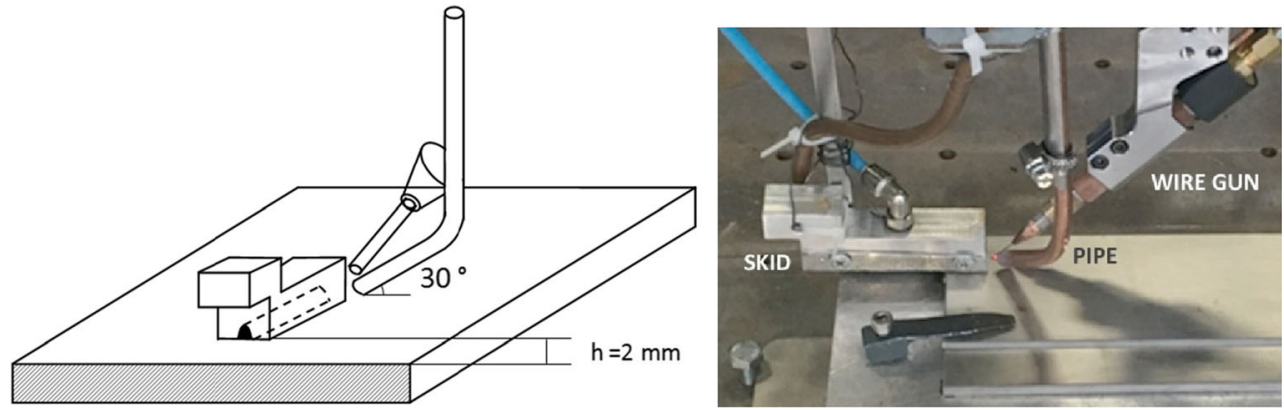

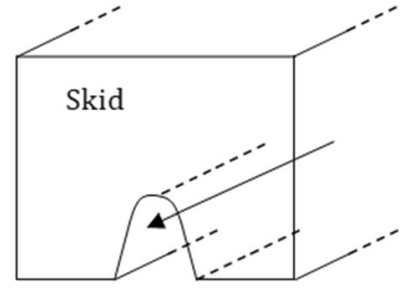

Fig. 4 Detail of the aluminum skid to shield the reported metal

Table 2 Levels of the processing factors

\begin{tabular}{lllll}
\hline Laser power $[\mathrm{W}]$ & 1250 & 1500 & & \\
Travelling speed $[\mathrm{mm} / \mathrm{min}]$ & 600 & 750 & & \\
Wire speed factor & 1.0 & 1.5 & 2.0 & 2.5 \\
\hline
\end{tabular}

compromise to achieve good quality and limit the overall size of the equipment, as additional devices are mandatory.

Commercial Ti-6Al-4V has been considered for both the substrate (i.e., 5-mm-thick plates) and the feeding wire. Since

Table 3 Processing conditions

\begin{tabular}{llllc}
\hline & $P[\mathrm{~W}]$ & $V_{f}[\mathrm{~mm} / \mathrm{min}]$ & $k$ & $V_{w}[\mathrm{~mm} / \mathrm{min}]$ \\
\hline 1 & 1250 & 600 & 1.0 & 600 \\
2 & 1250 & 600 & 1.5 & 900 \\
3 & 1250 & 600 & 2.0 & 1200 \\
4 & 1250 & 600 & 2.5 & 1500 \\
5 & 1250 & 750 & 1.0 & 750 \\
6 & 1250 & 750 & 1.5 & 1125 \\
7 & 1250 & 750 & 2.0 & 1500 \\
8 & 1250 & 750 & 2.5 & 1875 \\
9 & 1500 & 600 & 1.0 & 600 \\
10 & 1500 & 600 & 1.5 & 900 \\
11 & 1500 & 600 & 2.0 & 1200 \\
12 & 1500 & 600 & 2.5 & 1500 \\
13 & 1500 & 750 & 1.0 & 750 \\
14 & 1500 & 750 & 1.5 & 1125 \\
15 & 1500 & 750 & 2.0 & 1500 \\
16 & 1500 & 750 & 2.5 & 1875 \\
\hline
\end{tabular}

titanium is prone to oxidation, an apparatus (Fig. 3) has been developed for inert shielding of both the melted pool and the metal during solidification as a carryover of a prior patented device for welding [24]: two separate inert supplies have been required in this work, an aluminum tunnel-shaped skid (Fig. 4) [25] supplying helium at a constant flow rate of $9 \mathrm{~L} /$ min, atmospheric pressure over the deposited metal, in conjunction with a copper pipe, $2 \mathrm{~mm}$ diameter, supplying argon at a constant flow rate of $16 \mathrm{~L} / \mathrm{min}$, atmospheric pressure, to specifically shield the melting pool where metal wire is fed and fused by the laser beam. Although argon would be preferred in an industrial environment thanks to reduced costs, the reported metal required stronger shielding action; hence, helium has been supplied via the skid, whereas argon shielding was proved to be effective for the melted pool. A proper angle to position the pipe has been found before the experimental campaign.

Since positioning and stability of the wire with respect to the melting pool are crucial in DMD, specific actions have been taken. Namely, a coaxial laser pointer with respect to the processing beam has been used to position the wire tip; stability along the drive path was assured by means of additional features of the wire gun such as drive roll alignment devices and wire guides.

Many variables are involved in DMD; therefore, a systematic approach has been taken. The main inputs have been selected based on the referred literature [10]; hence, the effects of laser power $P$, travelling speed $V_{f}$, and wire speed factor $k$ (i.e., the wire to laser speed ratio) have been discussed in condition of focused beam, resulting in a processing laser beam diameter of $0.3 \mathrm{~mm}$ on the metal wire. As the latter has a diameter of $1 \mathrm{~mm}$, the driving idea of this campaign is to investigate the

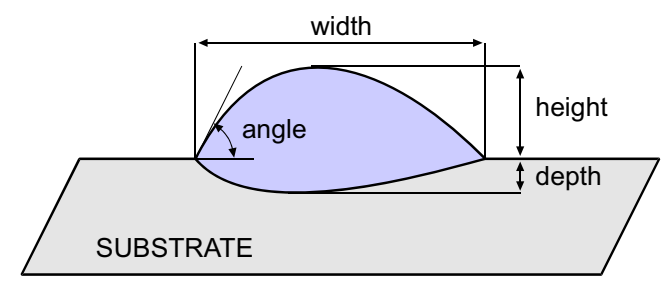

Fig. 5 Scheme of the geometrical responses in the cross-section 
possibility of achieving fusion of the substrate by means of conduction via the wire; a reduction of the HAZ is hence expected. As a consequence, the processing window has been properly adjusted with respect to the existing literature on the same subject [7] where larger spots are delivered; namely, a number of preliminary trials have been required so to result in valuable outcomes (i.e., preventing detachment, balling, and lack of clad). Improper experimental conditions resulted in no fusion at all, or excessive penetration in the substrate; these will be discussed in the relevant section.

A mixed, three-factor experimental plan has been set (Table 2); 16 processing conditions resulted (Table 3, the wire speed $V_{w}$ is given as a consequence of the wire speed factor). Three runs have been performed for each processing condition; a random test procedure has been arranged.

The geometry has been evaluated upon cross-cutting and chemical etching; three samples from each trace have been considered, and the results have been averaged among them to assess the statistical significance. Polishing to mirror finish and chemical etching with a solution consisting of $10 \%$ hydrofluoric acid, $15 \%$ nitric acid, and water at room temperature has been performed.

In agreement with common practice in DMD [22], a number of geometrical responses in the cross-section (Fig. 5) have been measured as a function of the governing parameters: width, depth, height, and shape angle at both sides of the reported metal. The ratio of the pores to the total fused area has been evaluated as well, in order to discuss the compliance to possible standards. Measurements have been conducted by means of conventional optical microscopy. Dilution indexing the affection of the substrate with respect to the reported metal has been considered: a chemical definition is usually given involving the weight percentage composition of the main alloying elements in the substrate with respect to the reported metal [5]; nevertheless, it has been shown that an alternative geometric definition can be given [26]; namely, the ratio of the fused (i.e., mixing) area of the substrate to the total area in the transverse cross-section can be measured. To a first approximation [27], this can be even given as

dilution $=\frac{\text { depth }}{\text { height }+ \text { depth }}$
The geometrical approximation involving depth and height has been used in this work, in compliance with other studies in the literature [10]. Moreover, Vickers microhardness testing has been performed in longitudinal and transverse scanning direction within each given cross-section; an indenting load of $0.300 \mathrm{~kg}$ has been used for a dwell period of $10 \mathrm{~s}$; a step of $165 \mathrm{~mm}$ has been allowed between consecutive indentations, in compliance with ISO standard [28] for hardness testing on metallic materials.

\section{Results and discussion}

To set the processing window, a proper outcome has been aimed in terms of repeatability and soundness (Fig. 6). As an example, some improper processing conditions outside of the processing window are presented: low power may prevent a continuous, homogeneous trace, as irregular fusion is experienced (Fig. 7); conversely, high power above a given threshold may lead to macroporosity (Fig. 8).

\subsection{Geometry}

With the sole exception of condition 1, all of the processing tests resulted in effective deposition; moreover, based on visual inspections, shielding is deemed to be effective, no cracks neither macropores resulted on the surface of the reported metal. The corresponding macrographs in the transverse cross-section have been considered; a sample among three runs for each processing condition is given (Tables 4 and 5). Based on the shape of the fusion zone, the regime of conduction instead of keyhole is inferred to occur: this is consistent with the aim of the approach, since fusion is mandatory for surface only, to the purpose of DMD. Then, the geometry has been evaluated (Table 6); a number of micropores have been found and will be addressed in the following.

At first, it is worth noting that although a slight effect of power is noticed on the trace width (Fig. 9), height is unaffected by laser power for a given processing speed (Fig. 10), as a consequence of the approach to focus the laser beam to the feeding wire.
Fig. 6 Trace aspect resulting with $1500 \mathrm{~W}$ laser power, $600 \mathrm{~mm} / \mathrm{min}$ travelling speed, and a wire speed factor of 1

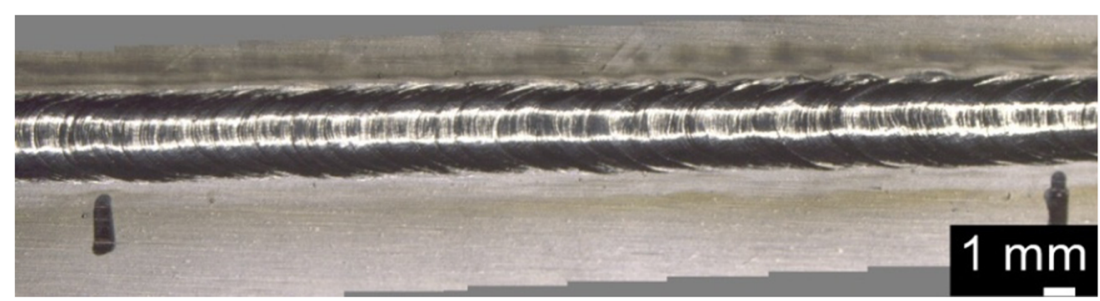


Fig. 7 Trace aspect resulting with $1000 \mathrm{~W}$ laser power, $600 \mathrm{~mm} / \mathrm{min}$ travelling speed, and a wire speed factor of 1

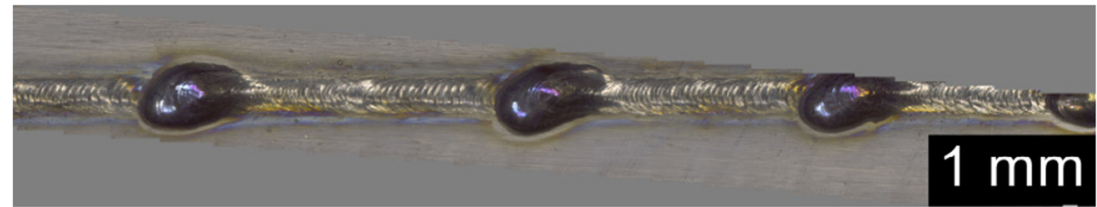

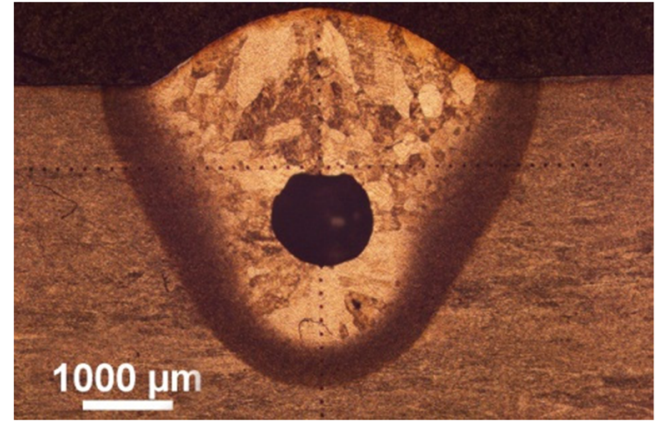

Fig. 8 Cross-section with macroporosity resulting with $2000 \mathrm{~W}$ laser power, $600 \mathrm{~mm} / \mathrm{min}$ travelling speed, and a wire speed factor of 1
Further and wider conclusions can be drawn when rearranging the results as a function of the feeding rate [10]. Namely, being $d_{w}$ the wire diameter and $\rho_{w}$ its density, the deposited wire mass per unit time can be given as follows:

$\dot{m}_{w}=\frac{\pi}{4} d_{w}^{2} \cdot V_{w} \cdot \rho_{w}=\frac{\pi}{4} d_{w}^{2} \cdot k \cdot s \cdot \rho_{w}$

A global clear view is benefited since all of the geometrical responses are given as a function of two processing variables, power and deposited wire mass per unit time (Fig. 11). As one may expect, any increase in deposited mass yields an increase in both width and height, conversely, a decrease results in penetration depth and

Table 4 Cross-section macrographs as resulting in the processing condition for a laser power of $1250 \mathrm{~W}$

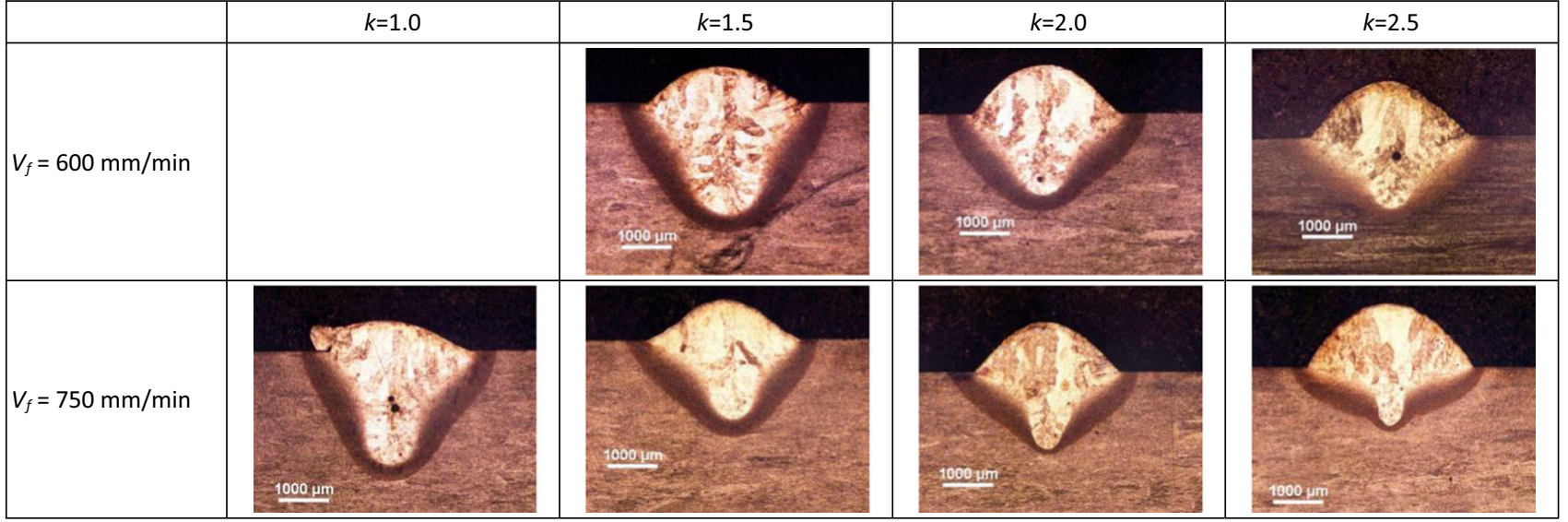

Table 5 Cross-section macrographs as resulting in the processing condition for a laser power of $1500 \mathrm{~W}$

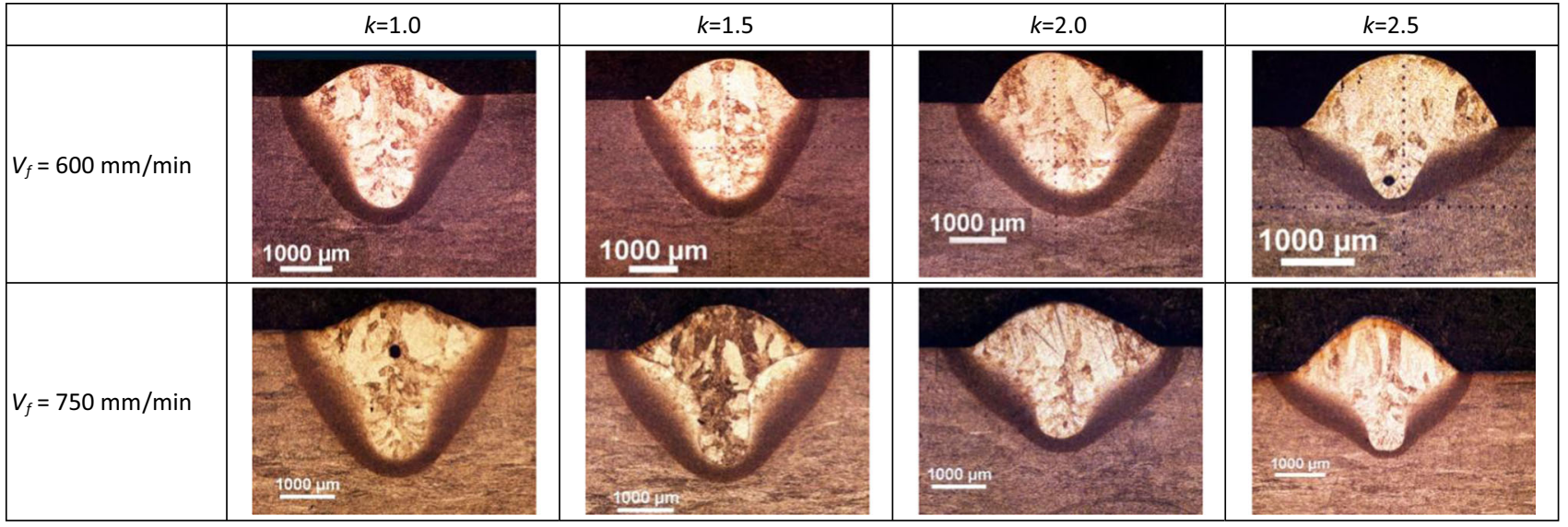


Table 6 Average geometrical responses in the cross-section

\begin{tabular}{|c|c|c|c|c|c|c|c|c|c|}
\hline & $P[\mathrm{~W}]$ & $V_{f}[\mathrm{~mm} / \mathrm{min}]$ & $k$ & Width [mm] & Height $[\mathrm{mm}]$ & Depth [mm] & Angle $\left[^{\circ}\right]$ & Dilution [\%] & Pore area $[\%]$ \\
\hline 1 & 1250 & 600 & 1.0 & & & & & & \\
\hline 2 & 1250 & 600 & 1.5 & 3.08 & 0.73 & 2.63 & 37 & 78 & 0.66 \\
\hline 3 & 1250 & 600 & 2.0 & 2.98 & 0.99 & 1.94 & 49 & 66 & 0.44 \\
\hline 4 & 1250 & 600 & 2.5 & 3.20 & 1.14 & 1.85 & 56 & 62 & 0.95 \\
\hline 5 & 1250 & 750 & 1.0 & 2.98 & 0.53 & 2.48 & 36 & 83 & 0.40 \\
\hline 6 & 1250 & 750 & 1.5 & 3.01 & 0.75 & 1.99 & 37 & 73 & 0.55 \\
\hline 7 & 1250 & 750 & 2.0 & 2.90 & 0.89 & 2.10 & 39 & 73 & 0.80 \\
\hline 8 & 1250 & 750 & 2.5 & 3.07 & 1.09 & 1.23 & 58 & 53 & 0.14 \\
\hline 9 & 1500 & 600 & 1.0 & 2.96 & 0.63 & 2.46 & 32 & 80 & \\
\hline 10 & 1500 & 600 & 1.5 & 3.06 & 0.76 & 2.26 & 42 & 75 & 1.05 \\
\hline 11 & 1500 & 600 & 2.0 & 3.18 & 0.94 & 1.67 & 43 & 63 & \\
\hline 12 & 1500 & 600 & 2.5 & 2.80 & 1.10 & 1.62 & 54 & 59 & 1.20 \\
\hline 13 & 1500 & 750 & 1.0 & 3.11 & 0.62 & 2.84 & 28 & 82 & 1.10 \\
\hline 14 & 1500 & 750 & 1.5 & 3.27 & 0.78 & 2.48 & 34 & 76 & 0.34 \\
\hline 15 & 1500 & 750 & 2.0 & 3.50 & 0.86 & 2.00 & 34 & 70 & \\
\hline 16 & 1500 & 750 & 2.5 & 3.27 & 1.07 & 1.69 & 44 & 61 & \\
\hline
\end{tabular}

dilution, since a larger part of energy is absorbed by the deposited mass, hence preventing the affection of the substrate. As regarding the shape angle, this is mainly ruled by an increase in height; therefore, larger angles result when increasing the deposition rate. Again, a slight effect on the responses is given by any change of power.

A number of micropores, ranging in size from 110 to $520 \mu \mathrm{m}$ and/or accounting for a maximum $1.3 \%$ of the total area of the fusion zone, have been found. In agreement with other findings on welding and DMD [22, 29] and welding [30], occasional pore formation is random and irrespective of the processing conditions. One may assume this would not result in rejection of parts at quality checks. Namely, usual international or customer standards for quality in laser welding have been borrowed [31], since no specific regulations are available at present for DMD: the highest level (class A) of the standard is matched in terms of both maximum allowed size $(0.75 \mathrm{~mm}$ at surface, 1.5 subsurface $)$ and accumulated length ( $3 \mathrm{~mm}$ at surface, $6 \mathrm{~mm}$ subsurface).
Fig. 9 Width and height as a function of power and wire speed factor, for a given processing speed of $600 \mathrm{~mm} / \mathrm{min}$
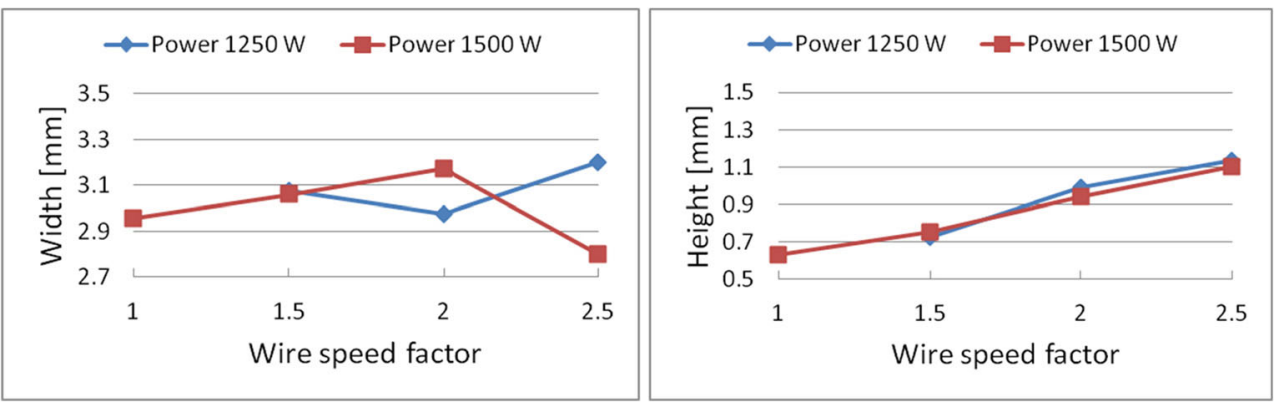

Fig. 10 Width and height as a function of power and wire speed factor, for a given processing speed of $750 \mathrm{~mm} / \mathrm{min}$
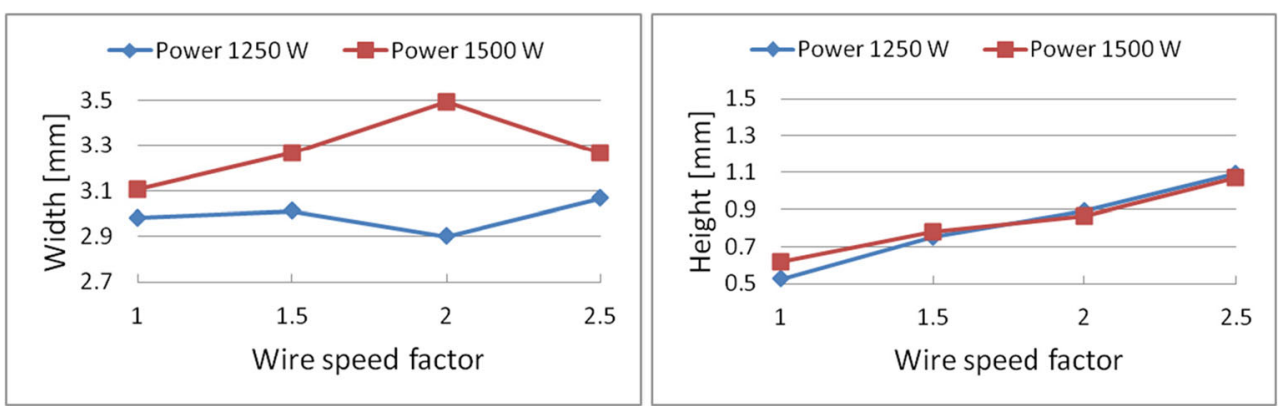

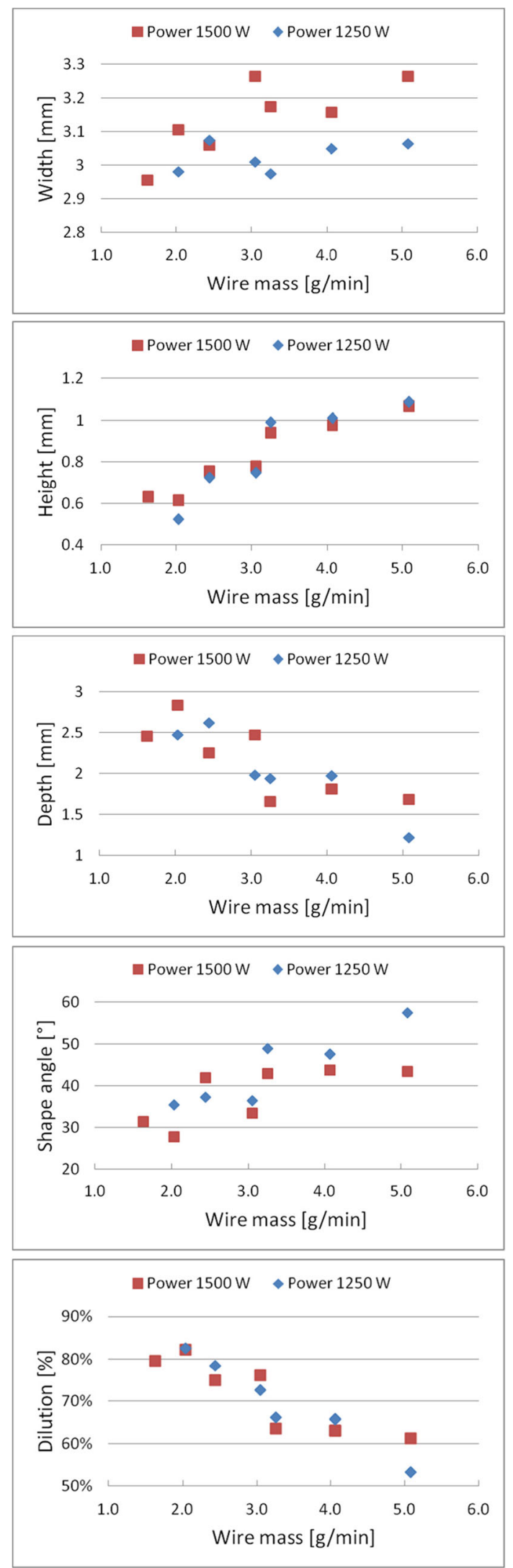

Fig. 11 Main geometrical responses as a function of power and deposited wire mass per unit time

\subsection{Microhardness and microstructure}

Based on the macrograph, an affection of the base metal has been noticed beyond the fusion zone; the extent of the HAZ has been discussed by means of microhardness testing in longitudinal and transverse scanning direction within the cross-section. In agreement with the literature [10, 29], higher hardness to an average $420 \mathrm{HV}$ resulted in the fusion zone with respect to a reference $335 \mathrm{HV}$ in the substrate as a consequence of finer microstructure as well as formation of acicular $\alpha^{\prime}$ martensite; an intermediate value of $370 \mathrm{HV}$ has been measured in the heat-affected zone instead (Fig. 12). Given the allowed 200- $\mu \mathrm{m}$ step between consecutive indentations, a maximum HAZ extent of $0.4 \mathrm{~mm}$ can be inferred.

Namely, a non-diffusional transformation of the original dark $\beta$-phase resulted in the fusion zone, while a mixture of acicular $\alpha^{\prime}$ martensite and primary bright $\alpha$-phases has been found in the HAZ (Fig. 13). Although the grain size depends on the thermal input of the processing condition [29], an attempt has been made to assess possible dependence of the maximum hardness on the processing parameters; very slight differences have been found to
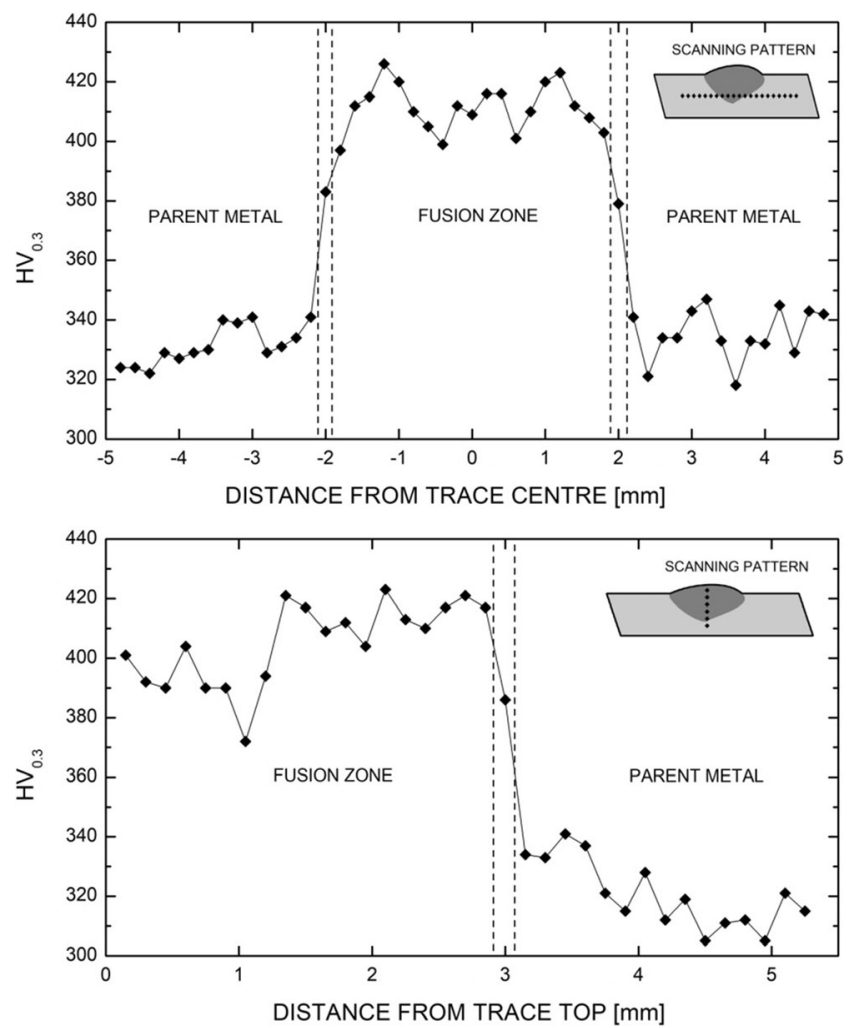

Fig. 12 Example of the microhardness trend in longitudinal and transverse scanning direction within the cross-section for a condition of $1500 \mathrm{~W}$ laser power, $600 \mathrm{~mm} / \mathrm{min}$ travelling speed, and a wire speed factor of 1 
Fig. 13 Micrograph in the sites of interest, resulting for a condition of $1500 \mathrm{~W}$ laser power, $600 \mathrm{~mm} /$ min travelling speed, and a wire speed factor of 1: unaffected primary bright $\alpha$ - and dark $\beta$ phases in the parent metal; acicular $\alpha^{\prime}$ martensite grains in the fusion zone

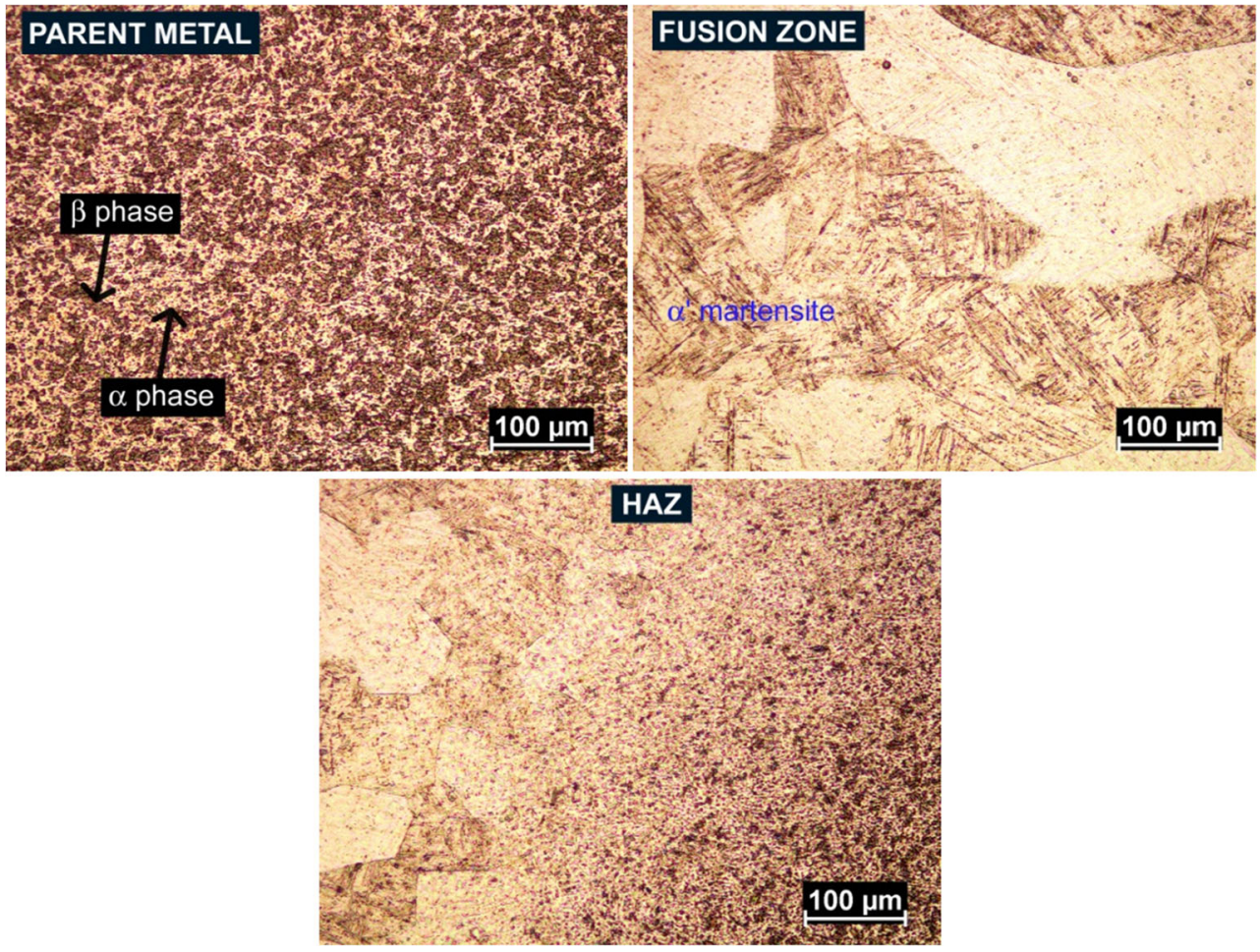

clearly infer these assumptions in the current investigating domain; definitely, a larger processing window both in terms of power and speed has been investigated when a dependence on the processing conditions has been noticed [14].

\section{Conclusions}

Directed metal deposition of titanium wire has been proven to be feasible. A number of main findings are given in the following.

- Aiming to additive fabrication, the proper processing condition (i.e., larger or higher traces) must be chosen depending on the scanning strategy.

- Random imperfections in the form of micropores have been found in the cross-section and should be properly addressed by means of non-destructive testing; nevertheless, since the maximum size and the total percentage with respect to the fusion zone have been found to comply with the referred standards, one may expect the processing conditions would not result in rejection of parts at quality checks.

- An increase of microhardness results as a consequence of non-diffusional martensitic transformation and finer microstructure, with reduced extent of the heat-affected zone in the cross-section.
Open Access This article is distributed under the terms of the Creative Commons Attribution 4.0 International License (http:// creativecommons.org/licenses/by/4.0/), which permits unrestricted use, distribution, and reproduction in any medium, provided you give appropriate credit to the original author(s) and the source, provide a link to the Creative Commons license, and indicate if changes were made.

\section{References}

1. Graf B, Ammer S, Gumenyuk A, Rethmeier M (2013) Design of experiments for laser metal deposition in maintenance, repair and overhaul applications. Procedia CIRP 11:245-248

2. Gibson I, Rosen D, Stucker B (2015) Additive manufacturing technologies. Springer, London

3. Lujering G, Williams J (2007) Titanium. Springer, New York

4. Dutta B, Froes F (2016) The additive manufacturing of titanium alloys. Butterworth-Heinemann, Oxford

5. Toyserkani E, Khajepour A, Corbin S (2005) Laser cladding. CRC Press, Boca Raton

6. Caiazzo F, Alfieri V, Corrado G, Argenio P, Barbieri G, Acerra F, Innaro V (2017) Laser beam welding of a Ti-6Al-4V support flange for buy-to-fly reduction. Metals 7:183

7. Brandl E, Leyens C, Palm F (2011) Mechanical properties of additive manufactured Ti-6Al-4V using wire and powder based processes. Mater Sci Eng 26

8. Steen W, Mazumder J (2010) Laser material processing. Springer, London

9. Ocelik V, Nenadl O, Palavra A, De Hosson T (2014) On the geometry of coating layers formed by overlap. Surf Coat Technol 242: 54-61

10. Demir A (2018) Micro laser metal wire deposition for additive manufacturing of thin-walled structures. Opt Lasers Eng 100:9-17 
11. Xu X, Mi G, Luo Y, Jiang P, Shao X, Wang C (2017) Morphologies, microstructures and mechanical properties of samples produced using laser metal deposition with $316 \mathrm{~L}$ stainless steel wire. Opt Lasers Eng 94:1-11

12. Abioye T, Folkes J, Clare A (2013) A parametric study of Inconel 625 wire laser deposition. J Mater Process Technol 213:2145-2151

13. Ding D, Pan Z, Cuiuri D, Li H (2015) Wire-feed additive manufacturing of metal components: technologies, developments and future interests. Int J Adv Manuf Technol 1-17. doi:https://doi. org/10.1007/s00170-015-7077-3

14. Brandl E, Michailov V, Viehweger B, Leyens C (2011) Deposition of Ti-6Al-4V using laser and wire, part I: microstructural properties of single beads. Surf Coat Technol 206:1120-1129

15. Hussein N, Segal J, McCartney D, Pashby I (2008) Microstructure formation in Waspaloy multilayer builds following direct metal deposition with laser and wire. Mater Sci Eng A 497:260-269

16. Mok SH, Bi G, Folkes J, Pashby I, Segal J (2008) Deposition of Ti$6 \mathrm{Al}-4 \mathrm{~V}$ using a high power diode laser and wire, part II: investigation on the mechanical properties. Surf Coat Technol 202:46134619

17. Brandl E, Baufeld B, Leyens C, Gault R (2010) Additive manufactured Ti-6Al-4V using welding wire: comparison of laser and arc beam deposition and evaluation with respect to aerospace material specification. Phys Procedia 5:595-606

18. Baufeld B, van der Biest O (2009) Mechanical properties of Ti-6Al$4 \mathrm{~V}$ specimens produced by shaped metal deposition. Sci Technol Adv Mater 10:1-10

19. Lin J, Lv Y, Liu Y, Xu B, Sun Z, Li Z, Wu Y (2016) Microstructural evolution and mechanical properties of Ti-6Al-4V wall deposited by pulsed plasma arc additive manufacturing. Mater Des 102:30-40

20. Shi X, Ma S, Liu C, Wu Q, Lu J, Liu Y, Shi W (2017) Selective laser melting-wire arc additive manufacturing hybrid fabrication of Ti-6Al-4V alloy: microstructure and mechanical properties. Mater Sci Eng A 684:196-204
21. Arrizubieta J, Klocke F, Klingbeil N, Arntz K, Lamikiz A, Martinez $\mathrm{S}$ Evaluation of efficiency and mechanical properties of Inconel 718 components built by wire and powder laser material deposition. Rapid Prototyp J 23(6):965-972

22. Caiazzo F, Alfieri V, Argenio P, Sergi V (2017) Additive manufacturing by means of laser-aided directed metal deposition of 2024 aluminium powder: investigation and optimization. Adv Mech Eng 9(8):1-12

23. Syed W, Pinkerton A, Li L (2005) A comparative study of wire feeding and powder feeding in direct diode laser deposition for rapid prototyping. Appl Surf Sci 1-4:268-276

24. Caiazzo F, Sergi V, Corrado G, Alfieri V, Cardaropoli F, Automated apparatus of laser beam welding. Patent EP2931468 (A1), 2110 2015

25. Caiazzo F, Alfieri V, Cardaropoli F, Sergi V (2017) Investigation on edge joints of Inconel 625 sheets processed with laser welding. Opt Laser Technol 93:180-186

26. Abbas G, West D (1991) Laser surface cladding of stellite and stellite-SiC composite deposits for enhanced hardness and wear. Wear 143:353-363

27. Ya W, Pathiraj B, Liu S (2016) 2D modelling of clad geometry and resulting thermal cycles during laser cladding. J Mater Process Technol 230:217-232

28. EN ISO 6507-1 (2005) Metallic materials — Vickers hardness testpart 1: test method, Geneva: ISO

29. Caiazzo F, Alfieri V, Fierro I, Sergi V (2014) Investigation and optimization of disk-laser welding of $1 \mathrm{~mm}$ thick Ti-6Al-4V titanium alloy sheets. Adv Mech Eng

30. Alfieri V, Caiazzo F, Sergi V (2015) Autogenous laser welding of AA2024 aluminium alloy: process issues and bead features. Procedia CIRP 33:407-412

31. AWS D17.1M:2017, Specification for fusion welding for aerospace applications, Miami, FL: American Welding Society, 2017 